Journal of

Molecular Microbiology

and Biotechnology

\title{
Physiology of Acetic Acid Bacteria in Light of the Genome Sequence of Gluconobacter oxydans
}

\author{
Uwe Deppenmeier ${ }^{\mathrm{a}} \quad$ Armin Ehrenreich $^{\mathrm{b}}$ \\ ${ }^{a}$ Institut für Mikrobiologie und Biotechnologie der Rheinischen Friedrich-Wilhelms Universität Bonn, Bonn, \\ und ${ }^{b}$ Abteilung für Angewandte und Genomische Mikrobiologie, Institut für Mikrobiologie und Genetik der \\ Georg-August Universität Göttingen, Göttingen, Deutschland
}

\section{Key Words}

Acetic acid bacteria - Biotechnology $\cdot$ Pyrroloquinoline quinone-dependent dehydrogenases $\cdot$ Vinegar

\begin{abstract}
Acetic acid bacteria are a distinct group of microorganisms within the family Acetobacteriaceae. They are characterized by their ability to incompletely oxidize a wide range of carbohydrates and alcohols. The great advantage of these reactions is that many substrates are regio- and stereoselectively oxidized. This feature is already exploited in several combined biotechnological-chemical procedures for the synthesis of sugar derivatives. Therefore, it is important to understand the basic concepts of this type of physiology to construct strains for improved or new oxidative fermentations. Based on the genome sequence of Gluconobacter oxydans, we will shed light on the central carbon metabolism, the composition of the respiratory chain and the analysis of uncharacterized oxidoreductases. In this context, the role of membrane-bound and -soluble dehydrogenases are of major importance in the process of incomplete oxidation. Other topics deal with the question of how these organisms generate energy and assimilate carbon. Furthermore, we will discuss how acetic acid bacteria thrive in their nutrient-rich environment and how they outcompete other microorganisms.

Copyright ๑ 2008 S. Karger AG, Basel
\end{abstract}

\section{Introduction}

Acetic acid bacteria are obligate aerobic, Gram-negative, rod-shaped bacteria that are well known for their potential to incompletely oxidize a wide variety of sugars, alcohols and polyols [De Ley and Swings, 1984; De Ley et al., 1984]. Due to their capability of rapid and nearly quantitative stereo- and regiospecific incomplete oxidation reactions they can be used in a wide variety of biotechnological processes where they perform oxidation steps that are either impossible by classical organic chemistry or that would have poor yields due to the required protective group chemistry [Deppenmeier et al., 2002; Gupta et al., 2001]. In this sense, acetic acid bacteria can be seen as 'living oxidative catalysts' that perform very specific oxidation reactions and channel the released electrons to molecular oxygen. These biotechnological processes are called 'oxidative fermentations' [Adachi et al., 2003]. Because many acetic acid bacteria generate relatively low growth yields [Olijve and Kok, 1979], they are very well suited for application in biotechnology. The organisms convert only small amounts of the substrate to biomass and can thrive in concentrated sugar solutions, for example up to $30 \%(\mathrm{w} / \mathrm{v})$ glucose [Sievers and Swings,

Both authors contributed equally to this review.

\section{KARGER}

Fax +4161306 1234

E-Mail karger@karger.ch

www.karger.com
C 2008 S. Karger AG, Basel

$1464-1801 / 09 / 0162-0069 \$ 26.00 / 0$

Accessible online at:

www.karger.com $/ \mathrm{mmb}$
Armin Ehrenreich

Abteilung für Angewandte und Genomische Mikrobiologie

Institut für Mikrobiologie und Genetik der Georg-August Universität Göttingen

Grisebachstrasse 8, DE-37077 Göttingen (Germany)

Tel. +49551393 833, Fax +49551391 2181, E-Mail aehrenr@gwdg.de 
2005]. Despite their usefulness and promising future potential, relatively little is known about the metabolism and general growth physiology of acetic acid bacteria and this severe lack of understanding hampers the rational design and optimization of biotechnological processes. Major questions for applied microbiology concern the control of the generation of biomass in the initial phase of oxidative fermentations for fast substrate conversion, how to quantitatively convert high substrate concentrations, what the full oxidative potential of these organisms is and how it can be exploited. In addition to these questions, it is important to understand the basic concepts of this type of organism to construct strains for improved or new oxidative fermentation. What is the role of the set of membrane-bound and -soluble dehydrogenases and how do these organisms generate energy and assimilate carbon? In this review we will give an overview about the central metabolism of acetic acid bacteria with special respect to the data obtained from the genome sequence of G. oxydans.

\section{Taxonomy and Physiology of Acetic Acid Bacteria}

Acetic acid bacteria are a monophyletic group within the family Acetobacteriaceae that belongs to the order Rhodospirillales as part of the Alphaproteobacteria. Acetic acid bacteria are represented by the genera Acetobacter, Acidomonas, Asaia, Gluconacetobacter, Gluconobacter and Kozakia, which are all acidophilic bacteria, capable of growth at $\mathrm{pH} 4.5$ with a strict oxidative metabolism [Sievers and Swings, 2005]. Typical habitats are fruits, nectar, palm wine, tea fungus, kefir, fermented food or vinegar fermentations. With the exception of Acidomonas methanolica, acetic acid bacteria are oxidase-negative indicating that they lack a cytochrome $c$ oxidase [Matsushita et al., 1994]. They have a pronounced tendency for incomplete oxidation converting primary alcohols to acids or secondary alcohols to ketones. The most prominent process is the oxidation of ethanol to acetic acid, which is conducted by all genera of acetic acid bacteria with the exception of Asaia [Katsura et al., 2001; Yamada et al., 2000]. With respect to further utilization of acetate, the acetic acid bacteria can be divided in two physiologic groups: members of the genera Acetobacter, Acidomonas, Asaia, Gluconacetobacter and Kozakia are able to oxidize acetate and lactate completely to $\mathrm{CO}_{2}$ (over oxidation) via the TCA cycle and the glyoxylic acid shunt [Chinnawirotpisan et al., 2003; Leisinger, 1965].
The second physiologic group is formed by members of the genus Gluconobacter. These organisms lack the glyoxylic acid shunt and the TCA cycle is incomplete [Greenfield and Claus, 1972; Prust et al., 2005]. Therefore, they are not able to completely oxidize acetate or lactate to $\mathrm{CO}_{2}$. Other characteristic and taxonomic relevant reactions of Gluconobacter species are the oxidations of sugars to their corresponding sugar acids. A well-known example is the oxidation of glucose to gluconic acid, which can be further oxidized by many species to 2-keto-gluconic acid, 5-keto-gluconic acid and 2,5-diketo-gluconic acid [Hölscher et al., 2006, and this issue]. Secondary alcohols are oxidized to ketones in a process referred to as ketogenesis. These oxidations are carried out by two sets of dehydrogenases, one composed of soluble enzymes and the other made of membrane-bound enzymes (see below) [Adachi et al., 2003].

The electron transport chains of acetic acid bacteria, with the exception of $A$. methanolica, contain cy tochrome $c$, ubiquinol and a terminal ubiquinol oxidase of the cytochrome $o$ or cytochrome $d$ type [Matsushita et al., 1994]. Acetobacter species additionally contain an ubiquinol oxidase of the $a_{1}$ type. Only A. methanolica contains a cytochrome $c$ oxidase when grown on methanol [Chan and Anthony, 1991]. Gluconobacter, Gluconacetobacter as well as Acidomonas, Kozakia and Asaia use ubiquinones of the Q-10 type as electron carrier in their cytoplasmic membranes. In contrast, Acetobacter possesses ubiquinone of the Q-9 type as major ubiquinone [Franke et al., 1999; Yamada et al., 1997].

The taxonomy of acetic acid bacteria changed dramatically over the last decade. The comparison of rRNA sequences resulted in the creation of new genera and lead to a reclassification of several well-known species. Recently, two genera of acetic acid bacteria have been introduced. The first one is the genus Asaia [Katsura et al., 2001; Yamada et al., 2000], and the second is represented by the single species Kozakia baliensis [Lisdiyanti et al., 2002]. The genus Gluconobacter prefers sugar enriched environments like fruits, flowers, honey-bees, palm sap, cider, beer, soft drinks [Gupta et al., 2001] and forms a coherent, closely related phylogenetic cluster that currently contains the five species - G. oxydans, G. frateurii, G. cerinus, G. albidus, and G. thailandicus [Euzéby, 2005; Yamada et al., 1999]. One taxonomic feature is that Gluconobacter species possess polar flagella. Recent results indicate that the formation of flagella is only observable under specific growth conditions, e.g., G. oxydans $621 \mathrm{H}$ is motile only under low oxygen conditions [Ehrenreich, unpubl. results]. In contrast, members of the genera Ace- 
tobacter and Gluconacetobacter form peritrichous flagella. Acetic acid bacteria typically thrive in habitats with high concentrations of carbon source. Therefore, growth may be limited by other nutrients or factors. Some acetic acid bacteria are capable of nitrogen fixation, such as Gluconacetobacter diazotrophicus, Gluconacetobacter johannae and Gluconacetobacter azotocaptans [Sievers and Swings, 2005]. The ability to fix molecular nitrogen is certainly of advantage in these environments.

Acetic acid bacteria, with the exception of one recent report [Greenberg et al., 2006], are not known to be pathogenic to humans or animals but can induce bacterial rot of apples and pears. Furthermore, some strains cause fruit infections like the so-called pink disease in pineapples that results in pinkish discolorations in canned pineapples. They can also spoil beverages like beer, wine or other liquor spirits [Drysdale and Fleet, 1988].

Acetic acid bacteria produce a variety of exopolysaccharides [Moonmangmee et al., 2002a] such as levans (from sucrose), cellulose, and acetan (an acidic polysaccharide with similarities to xanthan). These polysaccharides are responsible for biofilm formation and retention of acetic acid bacteria in fixed-bed reactors. Cellulose production by Gluconacetobacter xylinum and some other species is responsible for the massive biofilm formation that can be observed at the surface of unstirred alcoholic liquids during the formation of vinegars. Another example is the tea fungus, which is a cellulosic pellicle layer that produces a pleasantly sour, refreshing aroma on sweetened black tea [Chen and Liu, 2000]. The aroma results from ethanol, acetate and gluconic acid generated by yeasts and acetic acid bacteria. Cellulose is synthesized by G. xylinum by a membrane-bound cellulose synthase and is secreted from the longitudinal axis [Delmer and Amor, 1995; Ross et al., 1991]. Cellulose formed by acetic acid bacteria is highly pure in comparison to cellulose of plant origin, allowing its use for wound dressing, skin substitutions, chewing gum, food stabilizers and additive to high-quality papers [Czaja et al., 2006; Ross et al., 1991].

\section{The Physiology of Acetic Acid Bacteria Predicted from the Genome Sequence of Gluconobacter oxydans $621 \mathrm{H}$}

Most aerobic bacteria oxidize their carbon sources completely to carbon dioxide and water. Only under certain growth conditions some microorganisms show the phenomenon of incomplete oxidation, or 'overflow metabolism', especially when high amounts of nutrients are available. In contrast, acetic acid bacteria oxidize their substrates incompletely even under 'normal' growth conditions. Among them is Gluconobacter oxydans, which is famous for the incomplete oxidation of a broad range of carbohydrates and alcohols. The corresponding products (aldehydes, ketones and organic acids) are secreted almost completely into the medium. The organism is able to grow in highly concentrated sugar solutions and at low $\mathrm{pH}$ values. High oxidation rates correlate with low growth yields, making Gluconobacter strains suitable objects for industrial application [Deppenmeier et al., 2002]. Recently, the complete genome of $G$. oxydans $621 \mathrm{H}$ was sequenced [Prust et al., 2005]. The genome data provide a rich source for metabolic reconstruction of the pathways leading to industrially important products derived from sugars and alcohols. We identified more than 75 genes by bioinformatic tools that encode potential oxidoreductases with unknown substrate spectra. These results may be used to develop strategies for the employment of G. oxydans for a much greater variety of incomplete oxidations and possible new industrial applications. The major findings from the genome sequence are summarized below.

\section{Respiratory Chain}

The respiratory chain is the key element of the oxidative metabolism in G. oxydans. Biochemical experiments and the data of the genome-sequencing project enable us to draw a detailed model of the membrane-bound electron transport system (fig. 1). The organism contains a gene encoding the type II NADH dehydrogenase (NDH2 ) that is composed of a single subunit and does not translocate protons. In contrast, a proton-pumping NADH:ubiquinone oxidoreductase (complex I) is absent. Two operons were found which encode quinol oxidases of the $b o_{3}$ type and of the $b d$ type, respectively (fig. 1). The former protein has been characterized and it was shown that the purified enzyme generates an electrochemical proton gradient when it is reconstituted into proteolipids [Matsushita et al., 1987]. The $b d$-type quinol oxidase is encoded by the genes gox0278 and gox0279. This enzyme probably represents the cyanide-insensitive terminal oxidase, which is produced at low $\mathrm{pH}$ values [Matsushita et al., 1989]. In accordance, DNA microarray data indicated elevated transcription of the genes encoding the $b d$-type quinol oxidase at pH 3.5 as compared to $\mathrm{pH} 5.5$ [Ehrenreich, unpubl. data]. In contrast to the Escherichia coli bdtype oxidase, the enzyme of G. oxydans is obviously not used to adopt to varying $\mathrm{O}_{2}$ concentrations because there is no altered expression of the corresponding genes in the course of changes in oxygen partial pressure [Ehrenreich, 


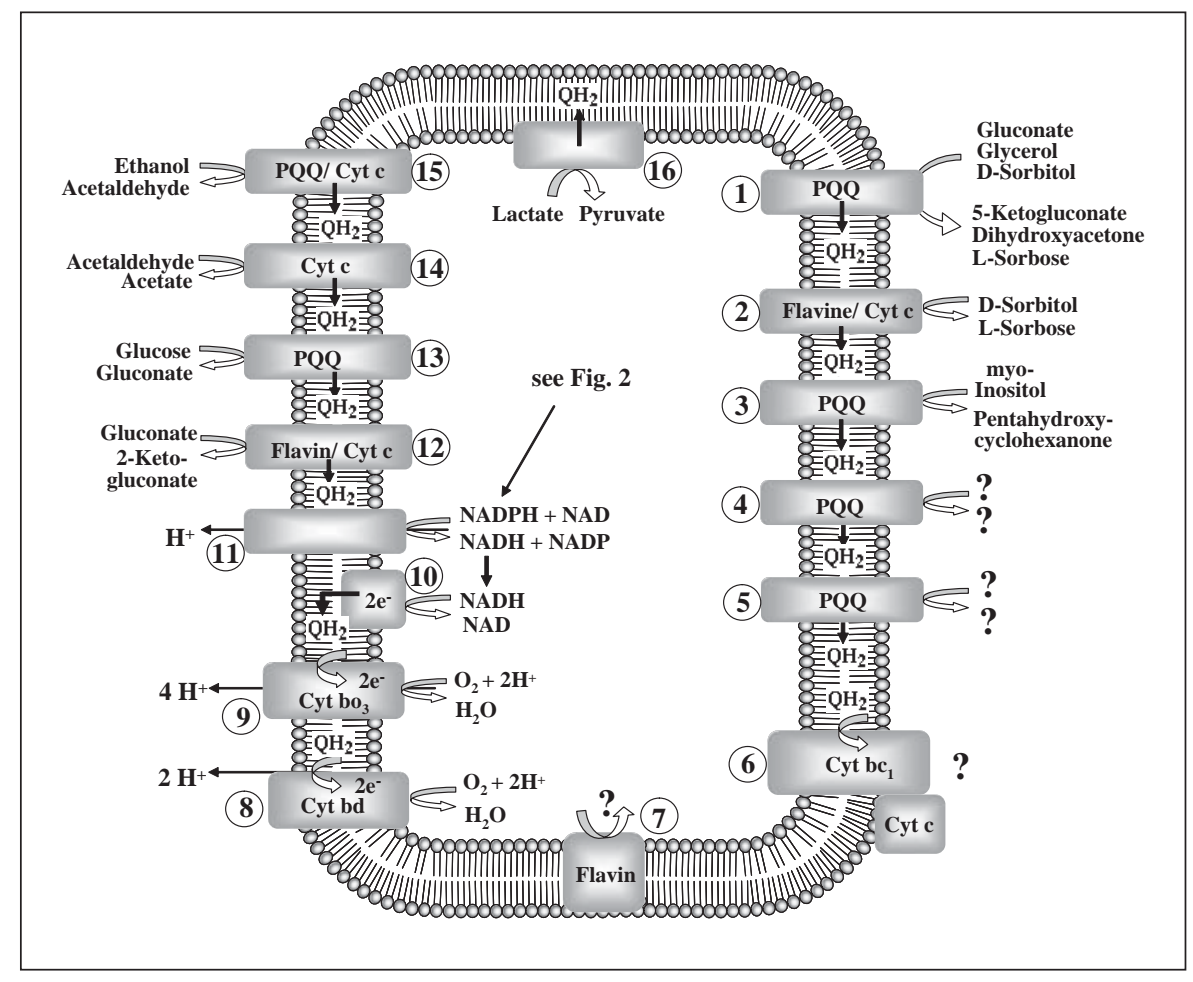

Fig. 1. Respiratory chain of G. oxydans $621 \mathrm{H}$. (1) Glycerol/sorbitol/gluconate dehydrogenase (SldAB; GOX854-855), (2) sorbitol dehydrogenase (GOX2094-2097), (3) PQQ-dependent myoinositol dehydrogenase (GOX1857), (4) uncharacterized membranebound quinoprotein (GOX1441), (5) uncharacterized membranebound quinoprotein (GOX0516), (6) ubiquinol:cytochrome $c$ oxidoreductase (GOX0565-0567), (7) uncharacterized flavincontaining dehydrogenase (GOX2251), (8) quinol oxidase (bdtype) (GOX0278-0279), (9) quinol oxidase (bo 3 -type) (GOX19111914), (10) NADH-dehydrogenase (type II), (11) membrane-bound transhydrogenase (GOX0310-0312), (12) membrane-bound gluconate-2-dehydrogenase (GOX1230-1232), (13) PQQ-dependent glucose dehydrogenase (GOX0265), (14) membrane-bound acetaldehyde dehydrogenase (GOX0585-0587), (15) PQQ-dependent alcohol dehydrogenase (GOX1067-1068), (16) membrane-bound lactate dehydrogenase (GOX1253). The membrane-bound dehydrogenases transfer electrons to ubiquinone to form the reduced cofactor ubiquinol $\left(\mathrm{UQH}_{2}\right)$. Question marks indicate that the substrates and products of the enzyme reaction are not known. unpubl. results]. Interestingly, genes encoding a ubiquinol:cytochrome $c$ oxidoreductase $\left(b c_{1}\right.$ complex) were identified in the genome and also found to be expressed during growth [Ehrenreich, unpubl. results]. The function of this protein complex is unclear because a cytochrome $c$ oxidase (complex IV) is missing in this organism and thus reduced cytochrome $c$ cannot be reoxidized.

Many intracellular dehydrogenases transfer electron onto $\mathrm{NADP}^{+}$-forming $\mathrm{NADPH}+\mathrm{H}^{+}$(fig. 2). For a long time it was a matter of debate how this cofactor is reoxidized. The genome data revealed the presence of an operon composed of three genes that encode a proton-translocating nicotinamide dinucleotide transhydrogenase in G. oxydans $621 \mathrm{H}$ (fig. 1). The amino acid sequences of the three subunits are highly homologous to the membrane- bound transhydrogenase from Rhodospirillum rubrum (pntAA, pntAB and pntB) [Buckley et al., 2000; Williams et al., 1994] and E. coli [Clarke et al., 1986; Tong et al., 1991]. PntAA is the soluble subunit of the enzyme from $R$. rubrum, equivalent to the relatively hydrophilic domain I that forms the $\mathrm{N}$-terminal part of the $\alpha$ polypeptide of the E. coli transhydrogenase, and which probably contains the $\mathrm{NAD}(\mathrm{H})$-binding site. This subunit is encoded by the gene gox0310 in G. oxydans. Gox0311 is a homologue of PntAB which corresponds to the strongly hydrophobic domain IIa at the C-terminus of the $\alpha$ polypeptide of the E. coli transhydrogenase. PntB in R. rubrum and Gox0312 in G. oxydans correspond to the E. coli $\beta$ polypeptide, which comprises the strongly hydrophobic domain IIb and the relatively hydrophilic domain III, thought to contain the NADP $(\mathrm{H})$-binding site 


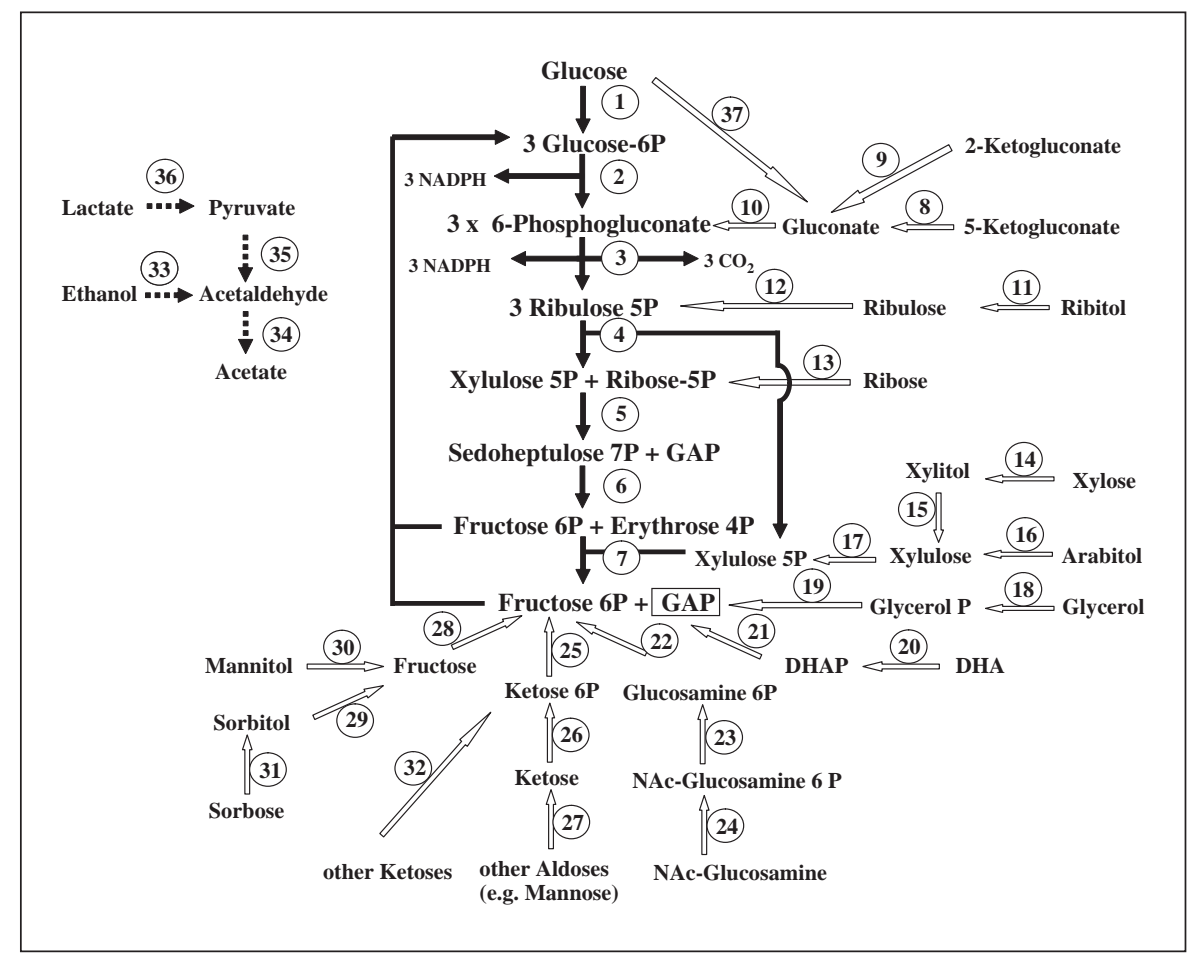

Fig. 2. Intracellular metabolism of sugars and sugar derivatives in G. oxydans $621 \mathrm{H}$. Reactions of the oxidative pentose phosphate pathway are indicated by black arrows. White arrows show reactions predicted to be involved in channeling sugars, polyols and their derivatives into the intermediary carbon metabolism. One GAP molecule is boxed indicating that it can be used for the synthesis of cell material or can be completely oxidized by re-entering the oxidative pentose phosphate pathway. Dashed arrows reveal the intracellular acetate metabolism. P = Phosphate; GAP = glyceraldehyde phosphate; $\mathrm{DHA}=$ dihydroxyacetone; $\mathrm{DHAP}=\mathrm{di}$ hydroxyacetone phosphate; Nac $=N$-acetyl. (1) Glucokinase (GOX2419), (2) glucose 6-phosphate dehydrogenase (GOX0145 or 2015), (3) 6-phosphogluconolactonase (GOX1707) and 6-phosphogluconate dehydrogenase (GOX1705), (4) ribulose-phosphate 3-epimerase (GOX1352) and ribose 5-phosphate isomerase (GOX1708), (5) transketolase (GOX1703), (6) transaldolase (GOX1704), (7) transketolase (GOX1703), (8) NADP-dependent gluconate 5-dehydrogenase (GOX2187), (9) putative gluconate 2dehydrogenase (GOX0218, 0417, or 0065), (10) gluconokinase (GOX1709), (11) putative ribitol dehydrogenase (GOX1899), (12) ribulokinase (GOX2186), (13) ribokinase (GOX2084), (14) putative xylose reductase (GOX0290, 2371, 1615, or 1462), (15) xylitol dehydrogenase (GOX0865), (16) arabitol dehydrogenase (GOX2181), (17) putative xylulose kinase (GOX2214), (18) glycerol kinase

[Clarke et al., 1986; Tong et al., 1991; Williams et al., 1994]. In many animal mitochondria and bacteria, transhydrogenases couple the reversible hydride transfer between $\mathrm{NADPH}+\mathrm{H}^{+}$and $\mathrm{NAD}^{+}$to proton translocation across a membrane [Bizouarn et al., 2002; Cotton et al.,
(GOX2090), (19) glycerol-3-phosphate dehydrogenase (GOX2088), (20) dihydroxyacetone kinase (GOX2222), (21) triosephosphate isomerase (GOX2217), (22) glucosamine-6-phosphate deaminase (GOX1470), (23) N-acetylglucosamine-6-phosphate deacetylase (GOX1473), (24) N-acetylglucosamine kinase (GOX1475), (25) putative sugar isomerase (GOX1040, 0455, or 1359), (26) putative sugar kinase $(2511,0090,0284$, or 0612), (27) aldose 1-epimerase (GOX0748), (28) fructokinase (GOX1182), (29) NAD(P)-D-sorbitol dehydrogenase (GOX1432), (30) arabitol dehydrogenase (GOX2181), (31) NADPH-dependent L-sorbose reductase (GOX0849), (32) putative sugar kinase (GOX2511, 0090, 0284, or 0612), (33) putative alcohol dehydrogenase (GOX0314), (34) acetaldehyde dehydrogenase (GOX1122), (35) pyruvate decarboxylase (GOX1081), (36) putative D-lactate dehydrogenase (GOX1253 or 2071), (37) soluble glucose dehydrogenase (GOX2015). The term putative indicates that the functional assignment is based on bioinformatic tools only and that there is biochemical proof of the predicted function. The KDPG pathway and the lower part of glycolysis (GAP to pyruvate) are not shown. NAD(P)H is formed in reactions 2 and 3 of figure 1 and by the oxidation of polyols and other reduced substrates (reactions 11, 15, 16, 19, 29, 30, 33, 34 in this figure). The NADH dehydrogenase catalyzes the oxidation of NADH (fig. 1). NADPH is converted by the transhydrogenase to $\mathrm{NADH}$, which is reoxidized by the NADH dehydrogenase (fig. 1).

2001]. In G. oxydans the enzyme may fulfill two functions: (i) the oxidation of NADPH derived from intermediary metabolism (fig. 2), and (ii) the transfer of protons across the membrane thereby contributing to the generation of the electrochemical proton gradient (fig. 1). We 
suggest that the resulting cofactor $\mathrm{NADH}+\mathrm{H}^{+}$is then reoxidized by the membrane-bound type II NADH dehydrogenase. However, under metabolic conditions that lead to limited NADPH formation, another possibility would be that the enzyme keeps the correct balance of the oxidation states between the pyridine nucleotides. NADH made by some dehydrogenases can additionally be used to reduce NADPH, which is required for biosynthetic reactions [Sauer et al., 2004].

In addition to the standard respiratory complexes mentioned above, G. oxydans contains many genes encoding membrane-bound dehydrogenases which transfer electrons into the respiratory chain (fig. 1). Various polyols and sugar alcohols are oxidized according to the Bertrand and Hudson rule [Kulhanek, 1989]. This rule states that polyols with a cis-arrangement of two secondary hydroxyl groups in D-configurations to the adjacent primary alcohol group (D-erythro configuration) are oxidized regioselectively to the corresponding ketoses. Most prominent are those enzymes that contain the cofactor pyrroloquinoline quinone (PQQ). The quinoproteins glucose dehydrogenase (producing gluconate), alcohol dehydrogenase (involved in acetate formation), and glycerol/sorbitol dehydrogenase (SldAB) belong to this group [Adachi et al., 2003]. The latter protein is the major polyol dehydrogenase in G. oxydans [Matsushita et al., 2003]. Its broad substrate specificity allows the oxidation of glycerol, gluconate, and D-sorbitol (fig. 1). The resulting products dihydroxyacetone, 5-ketogluconate, and L-sorbose are all of great biotechnological importance [Hekmat et al., 2003; Hermann et al., 2004; Hoshino et al., 2003]. These products are used for vitamin C production, for the synthesis of L-tartaric acid and find applications as a tanning agent, respectively. Other membrane-bound proteins like gluconate-2-dehydrogenase [Elfari et al., 2005; Shinagawa et al., 1981] and sorbitol dehydrogenase (SldSLC) [Shinagawa et al., 1982; Toyama et al., 2005] contain flavins that allow the interaction with components of the respiratory chain (fig. 1). The SldSLC sorbitol dehydrogenase is one of two identified proteins that catalyzes the oxidation of D-sorbitol to L-sorbose. In older reports this enzyme has been implicated in oxidation of D-sorbitol to D-fructose, which would have been of industrial relevance [Adachi et al., 2003], but newer studies do not support this finding, at least for the thermotolerant G. frateurii strain THD32 [Toyama et al., 2005]. There might also be a biotechnological application for the membrane-bound lactate dehydrogenases (gox1170) that are predicted to produce pyruvate in G. oxydans. Pyruvic acid is an important organic acid widely used in the chemical, drug, and agrochemical industries. Compared with the chemical method, biotechnological production of pyruvic acid is an alternative approach because of the low cost [Li et al., 2001].

The broad substrate specificity of many dehydrogenases might be the reason why most of the corresponding genes are not regulated based on the available carbon source, but rather are constitutively expressed [Ehrenreich, unpubl. data]. It has been shown that the membrane-bound dehydrogenases mentioned above are responsible for the rapid oxidation of biotechnologically important substrates [Pronk et al., 1989]. They all transfer electrons to the quinone pool in the cytoplasmic membrane that functions as source of electrons for the quinol dehydrogenases (fig. 1). The active sites of the dehydrogenases are exposed to the outside of the cell; hence substrates are directly oxidized in the periplasmic space. The products are released into the medium via porines present in the outer membrane of the Gram-negative bacteria. In the last decade, a variety of other PQQ-dependent dehydrogenase activities were purified from acetic acid bacteria. Among them are enzymes that oxidize quinate [Vangnai et al., 2004], meso-erythritol [Moonmangmee et al., 2002b], cyclic alcohols [Moonmangmee et al., 2001], and D-arabitol [Adachi et al., 2001a]. Unfortunately, we cannot identify the corresponding genes in the genome, as the genes encoding these proteins have not been characterized, but Matsushita et al. [2003] showed that the PQQ-containing glycerol dehydrogenase (sldAB) is accountable for meso-erythritol and D-arabitol oxidation in G. oxydans strain IFO3257.

In summary, the composition of the respiratory chain of $G$. oxydans reveals that the ability to translocate protons in the course of redox reactions is rather limited (fig. 1). Only the quinol oxidase of the $b o_{3}$ type is able to pump protons across the cytoplasmic membrane in the course of oxygen reduction $\left(4 \mathrm{H}^{+} / 2 \mathrm{e}^{-}\right)$. The $b d$-type oxidase does not pump protons, although the protein does generate a proton motive force [Miller and Gennis, 1985]. It has been shown that quinol oxidation in E. coli occurs near the periplasmic surface [Dueweke and Gennis, 1991], but that the protons used to form water are taken from the bacterial cytoplasm. Hence, the reaction is coupled to transmembrane charge separation and the generation of a membrane potential. The same may be true for the enzyme from G. oxydans. The only other enzyme that might contribute to the electrochemical proton gradient is the transhydrogenase described above. In summary, it is enticing to speculate that the respiratory chain of G. oxydans does not rely on NADH as electron donor but favors 
another mode of action that involves the great number of membrane-bound dehydrogenases. These enzymes use a broad spectrum of sugars, alcohols and polyols in the nutrient-rich habitats of $G$. oxydans and seem to connect them to the electron transport chain, coupling substrate oxidation directly to oxygen reduction and energy conservation.

G. oxydans is an obligate aerobic organism and does not grow in the absence of oxygen. In agreement with this is the finding that the genome does not contain genes encoding proteins involved in anaerobic respiration. The electrochemical proton gradient generated by the electron transport chain is used to generate ATP via an $\mathrm{F}_{1} \mathrm{~F}_{0^{-}}$ type ATP synthase. The complex is encoded by two gene clusters that are located at different positions on the chromosome. Cluster I (gox1110-1113) encodes the hydrophobic membrane-bound subunits and cluster II (gox13101314) contains the genes for the hydrophilic part of the enzyme [Prust et al., 2005].

\section{Intermediary Metabolism}

The oxidative pentose-phosphate pathway was reported to be the most important route for phosphorylative breakdown of sugars and polyols to $\mathrm{CO}_{2}$ in $G$. oxydans [Asai, 1968]. The presence of the enzymes of the pentose phosphate pathway was already demonstrated in 1955 [Hauge et al., 1955]. All genes encoding the enzymes of this pathway were identified form the genome sequence of G. oxydans 621H [Prust et al., 2005]. Furthermore, the genome reveals the presence of 13 genes encoding potential carbohydrate kinases and eight genes encoding potential sugar epimerases/isomerases. Therefore, we predict that this organism has the capability to take up and to channel many polyols, sugars and sugar derivatives into the oxidative pentose phosphate pathway (fig. 2). It is tempting to speculate that polyols are first oxidized by soluble dehydrogenases (see below). These products and other ketoses and aldoses are further modified by isomerases and epimerases. Finally, the compounds are phosphorylated by specific or unspecific kinases forming intermediates of the oxidative pentose phosphate pathway (fig. 2).

Early investigation showed that the Entner-Doudoroff pathway is active in cellulose-synthesizing Acetobacter strains and in Gluconobacter sp. [Kersters and De Ley, 1968]. In accordance, the genome sequences revealed that all proteins including the key enzymes 6-phosphogluconate dehydratase and KDPG aldolase can be formed by G. oxydans $621 \mathrm{H}$. In contrast, genes encoding phosphofructokinase and succinate dehydrogenase have not been found on the G. oxydans chromosome, indicating that the Embden-Meyerhof pathway is not functional and the citrate cycle is not complete and provide only biosynthetic precursors [Greenfield and Claus, 1972]. As affirmed by the genome sequence, a glyoxylic acid shunt is also absent. Furthermore, genes for phosphotransacetylase and acetate kinase are missing, suggesting that the organism is not able to produce acetate via intermediary metabolism, whereas an acetyl-CoA synthetase is present. This finding indicates that acetate may be assimilated and used as carbon source. A close inspection of the genome revealed that G. oxydans $621 \mathrm{H}$ cannot produce $\mathrm{C}_{6}$ sugars via gluconeogenesis because no open reading frame could be assigned that potentially encodes a phosphoenolpyruvate synthase or other phosphoenolpyruvatesynthesizing enzymes. This finding indicates that glucose derivatives and other $\mathrm{C}_{6}$ sugars are formed by the oxidative pentose phosphate pathway, for example during growth on pentoses or glycerol (fig. 2).

The lack of the gluconeogenesis pathway also explains why G. oxydans does not grow on lactate [De Ley, 1963]. Interestingly, we identified a gene encoding a pyruvate decarboxylase indicating that $G$. oxydans can produce acetaldehyde from pyruvate (fig. 2). A similar enzyme was found in Acetobacter pasteurianus and it was shown that the resulting acetaldehyde was oxidized to acetate by a soluble acetaldehyde dehydrogenase [Chandra et al., 2001].

PQQ is an important prosthetic group for a number of membrane-bound dehydrogenases [Hölscher and Görisch, 2006]. Growth experiments showed that G. oxydans $621 \mathrm{H}$ can synthesize PQQ de novo. The proteins necessary for PQQ production are encoded by the pqqA-E operon (gox0983-0987), which are highly homologous to proteins found in G. oxydans IFO 3293 [Felder et al., 2000]. Other dehydrogenases involved in electron transport contain cytochrome $c$ subunits. A close inspection of the genome revealed the presence of all genes for the synthesis and transport of heme $c$ and the maturation of cytochrome $c$ (gox1648-1652) [Felder et al., 2000; Prust et al., 2005]. Further analysis of the chromosome showed that G. oxydans contains metabolic pathways for the de novo synthesis of all amino acids, phospholipids, nucleotides and most vitamins [Prust et al., 2005].

\section{Intracellular Oxidoreductases}

As mentioned above, G. oxydans contains a variety of membrane-bound dehydrogenases for the oxidation of sugars, alcohols and polyols [De Ley et al., 1984; Matsushita et al., 1994]. However, there is an alternative route 
for the degradation of these substrates. The second set of enzymes are cytosolic NAD(P)-dependent oxidoreductases that catalyze reversible reactions (fig. 2). The genome sequence revealed that $G$. oxydans has several genes encoding enzymes of this class for the oxidation of polyols (e.g. gox2241 and gox1432) [Adachi et al., 2001b; Parmentier et al., 2005; Prust et al., 2005] and the reduction of ketogluconates and other ketosugars [Klasen et al., 1995]. The resulting intermediates are phosphorylated and further metabolized via the pentose phosphate pathway. In addition, several soluble oxidoreductases are present that oxidize ethanol, acetaldehyde or glucose. Hence, these oxidoreductases either participate in the synthesis of biosynthetic precursors or are involved in substrate degradation for the maintenance of cells in the stationary growth phase [Matsushita et al., 1994]. Two proteins were identified that might play a critical role in biotechnological applications. The first one is a NADPHdependent sorbose reductase that forms D-sorbitol from L-sorbose [Shinjoh et al., 2002], which is an important intermediate for industrial production of vitamin C. Intracellular D-sorbitol is oxidized by a sorbitol dehydrogenase-forming fructose that is channeled into the oxidative pentose phosphate pathway [Shibata et al., 2000] (fig. 2). In summary, L-sorbose is assimilated, resulting in a lower yield of the desired intermediate for vitamin production. The second enzyme is a xylitol dehydrogenase that reduces D-xylulose to xylitol [Sugiyama et al., 2003]. Since this pentahydroxy sugar prevents dental caries and has a similar degree of sweetness to sucrose it is used as an alternative natural sweetener. A biotechnological approach to produce this compound has been proposed [Sugiyama et al., 2003] that involves the conversion of glucose to arabitol by Pichia and Candida species. In a second step, arabitol could be oxidized to D-xylulose [Adachi et al., 2001b] and reduced to xylitol by G. oxydans.

\section{Analysis of Uncharacterized Oxidoreductases}

The G. oxydans genome contains 77 open reading frames that encode putative dehydrogenases/oxidoreductases of unknown functions [Prust et al., 2005]. Most of them are clearly expressed during growth on different substrates as determined by transcription analysis [Ehrenreich, unpubl. results]. The computer-based investigation of the corresponding amino acid sequences indicated that these uncharacterized oxidoreductases are members of the following protein families: (i) There are five members of the aldehyde dehydrogenase protein family. Very recently, two of these genes were overexpressed and the corresponding proteins were purified and analyzed for their activity. The enzymes oxidized a wide variety of aliphatic and aromatic aldehydes using NADP or NAD as a cofactor [Schweiger et al., 2006]. (ii) The organism contains 14 putative oxidoreductases of the short-chain dehydrogenases/reductase family that catalyzes the reversible oxidation of alcohols to aldehydes with the concomitant reduction of NAD. (iii) We identified four PQQ-dependent dehydrogenases, of which three are membrane-bound. One protein represents a periplasmic PQQ enzyme with a signal peptide and no further transmembrane helices. (iv) Six putative soluble oxidoreductases in G. oxydans belong to the aldo-keto reductase family that comprises a number of related monomeric NADPH-dependent oxidoreductases, such as aldehyde reductases and aldose reductases. Very recently, four of these enzymes were overproduced in E. coli and purified using the StrepTag technology. The proteins revealed interesting activities and reduced a variety of $\alpha$-diketones, $\alpha$-ketoaldehydes and 2-keto carboxylic acids [Deppenmeier, unpubl. results]. (v) 16 proteins were predicted to contain flavin. Among them are two FAD-dependent oxidoreductases, three FAD-linked oxidases, six FADdependent pyridine nucleotide reductases and two NADH:flavin oxidoreductases. In addition, we found several putative oxidoreductases belonging to other flavin-containing protein families, among them are two members of the flavin-containing amine oxidoreductases, molybdopterin/FAD-binding dehydrogenases, and one FMN-dependent dehydrogenase.

Three of these flavin-containing proteins have been purified and we could show that different substrates (e.g. quinones, $\alpha$-diketones and $\alpha$-vinylketones) are reduced by these enzymes [Deppenmeier, unpubl. results]. (vi) Five putative oxidoreductases belong to the zinc-binding dehydrogenase family. The G. oxydans proteins are assumed to be membrane-bound with their active centers facing the periplasm. One of these proteins reduces $\alpha$ diketones and short-chain aldehydes [Deppenmeier, unpubl. results]. (vii) Four genes in G. oxydans encode proteins of the nitroreductase family. These proteins are assumed to be involved in the reduction of nitrogen-containing compounds. (viii) Furthermore, there are five predicted 2-hydroxyacid dehydrogenases and (ix) 12 genes were identified that encode putative oxidoreductases with a $\mathrm{NAD}(\mathrm{P})$-binding Rossmann-fold domain.

\section{Nitrogen and Sulfur Metabolism}

G. oxydans $621 \mathrm{H}$ should be able to use ammonia as sole nitrogen source, which can be taken up by a specific 
ammonium transporter AmtB (Gox0743). Glutamate synthase (Gox1101) and glutamine synthetase (Gox18511852) should channel amino groups into the intermediary metabolism. Furthermore, we identified the nitrogen regulatory protein GlnK (Gox0744) which shows high similarity to the glnK/amtB operon of E. coli and Klebsiella pneumoniae [Jack et al., 1999; van Heeswijk et al., 1996]. Other gene products involved in regulation of nitrogen metabolism are encoded by an operon (gox04650469) that comprises $n r f A, n t r X, n t r Y, n t r C$ and nifR homologues. G. oxydans does not contain enzymes for the reduction of $\mathrm{N}_{2}$ or $\mathrm{NO}_{3}{ }^{-}$to $\mathrm{NH}_{4}{ }^{+}$and there is no $\mathrm{NAD}(\mathrm{P})$ specific glutamate dehydrogenase. Examination of the genome suggests that sulfate is the main source to produce sulfur-containing biomolecules. This hypothesis was verified by growth experiments on a mineral medium [Ehrenreich, unpubl. results]. Gene gox 1788 has been annotated as sulfate permease and the corresponding gene product may be responsible for sulfate uptake. The genes encoding proteins for sulfate reduction are organized in one putative operon (gox0925-0930). The genes gox0926 and gox0927 encode the phosphoadenosinephosphosulfate synthase (PAPS) system, which is a bifunctional enzyme. In a first step, sulfate adenylyltransferase catalyzes the formation of adenosine 5 '-phosphosulfate (APS) from ATP and inorganic sulfate. The second step is catalyzed by the adenylylsulfate kinase domain, which involves the formation of PAPS from enzymebound APS and ATP. The gene product Gox0930 may control the expression of this operon because it is homologous to the transcriptional activator gene $p s p F$, which controls transcription of the phage shock protein ( $p s p)$ operon in E. coli [Jovanovic et al., 1996]. The PAPS reductase and sulfite reductase are encoded by genes gox0928 and gox1198, respectively, and catalyze the reduction of $\mathrm{SO}_{3}{ }^{2-}$ to $\mathrm{S}^{2-}$. The combined action of the serine- $\mathrm{O}$-acetyltransferase (gox0747) and cysteine synthase (gox0660) give rise to the formation of cysteine from serine. NifS (Gox1369) and NifU (Gox0777) homologues are involved in $[\mathrm{Fe}-\mathrm{S}]$ cluster biosynthesis.

\section{Summary and Consequences}

The information gained from the genomic sequence of G. oxydans clearly indicate the uniqueness of the metabolism of this acetic acid bacterium. The physiology of acetic acid bacteria has been reviewed recently [Matsushita et al., 2004, 2005]. For G. oxydans it has been suggested that there is a life cycle with two distinct growth phases
[Olijve, 1978; Olijve and Kok, 1979; Weenk et al., 1984]. In the first growth phase, the variety and the broad substrate spectrum of the membrane-bound dehydrogenases is the key element in the process of incomplete oxidation (fig. 1). Sugars and alcohols in the nutrient-rich habitats of $G$. oxydans are rapidly oxidized, providing electrons for the respiratory chain. The short electron transport chain allows fast oxidation of the substrates. Additionally, it is evident that the coupling efficiency can be reduced by using the alternative oxidase of the $b d$ type to prevent an increase of the electrochemical membrane potential that would otherwise cause an inhibition of membrane-bound redox reactions. The oxidation products are released from the periplasm into the environment. At first sight this is a waste of nutrients, but Gluconobacter must be regarded as an organism that is adapted to very high concentrations of carbon source. Therefore, growth is likely to be limited by nutrients or factors other than the carbon source. It is a common strategy of many microorganisms to perform incomplete oxidations or a so-called 'overflow metabolism' in situations of high carbon concentrations, but Gluconobacter seems to have perfected this way of life. We also have to keep in mind that mainly sugar acids are formed that lead to a fast acidification of the habitat of G. oxydans giving an advantage to this extremely acid tolerant organism. Furthermore, these sugar acids are difficult to assimilate by other organisms. Therefore, the process of incomplete oxidation is an effective system for the deposit of organic compounds and inhibits the growth of competitors by lowering the $\mathrm{pH}$ value. The ineffective energy transduction of the electron transport chain is obviously compensated by its speed but results in low growth yields. Furthermore, we speculate that in the first growth phase, soluble dehydrogenases and the enzymes of the oxidative pentose phosphate pathway produce intermediates and NADPH for biosynthesis and do not provide reducing equivalents for energy conservation.

In the second phase of this life cycle, G. oxydans can take up the incompletely oxidized substrates and channels them into the oxidative pentose phosphate pathway by the set of soluble dehydrogenases, isomerases and kinases (fig. 2). Especially sorbose, 2-ketogluconate and 5ketogluconate have to be reduced (using NADPH) and need to be activated by phosphorylation. The products (6-phosphogluconate and fructose-6-phosphate) are intermediates of the oxidative pentose phosphate pathway and can be oxidized completely to get NADPH in excess (fig. 2). This process is coupled to the release of $\mathrm{CO}_{2}$ and it has been shown that the generation of carbon dioxide 
is increased dramatically in the second phase [Olijve, 1978]. NADPH is then transformed into NADH by the membrane-bound transhydrogenase and provides electrons for the respiratory chain. This process is probably much slower than the process of incomplete oxidation but allows the maintenance of the metabolism and the survival of the cells. This hypothesis is supported by growth experiments performed by Olijve and co-workers. Detailed analysis of substrate and product concentrations as well as $\mathrm{pH}$ values in batch cultures and chemostats clearly demonstrated the biphasic growth behavior. It is defined by the conversion of glucose to gluconate and the first growth phase, and a slow utilization of the incompletely oxidized products in the second growth phase using the oxidative pentose phosphate pathway [Olijve, 1978; Olijve and Kok, 1979; Weenk et al., 1984]. In summary, G. oxydans reveals a sophisticated strategy to grow and to survive in nutrient-rich environments by outcompeting other microorganisms. As mentioned above, species of the genera Acetobacter and Gluconacetobacter prefer alcohols (especially ethanol) as substrates and oxidize the compounds to corresponding carboxylic acids, whereas Gluconobacter strains are specialized to oxidize sugars and polyols incompletely. However, the overall lifestyle is similar and the hypothesis stated above also applies to Acetobacter and Gluconacetobacter strains. These organisms perform a fast conversion of ethanol to acetate using a set of membrane-bound dehydrogenases, thereby lowering the $\mathrm{pH}$ value and storing a carbon source in their habitat. Again, most other microorganisms cannot thrive in such an environment, giving the acetic acid bacteria a selective advantage. When ethanol is consumed Acetobacter and Gluconacetobacter strains can slowly assimilate acetate as carbon and energy source.

The rapid incomplete oxidation of carbon substrates by Gluconobacter strains is used for several biotechnological processes [Bremus et al., 2006; Deppenmeier et al., 2002; Gupta et al., 2001; Macauley et al., 2001]. The great advantage is that many substrates are regio- and stereoselectively oxidized. This feature is already employed in combined biotechnological-chemical synthesis of sugar derivatives that otherwise would only be obtained by complex protection group chemistry (e.g. vitamin $\mathrm{C}$ and the antidiabetic drug Miglitol). The organisms also can be used industrially to produce gluconic acid derivatives and dihydroxyacetone (a tanning agent). In addition, $G$. oxydans strains produce compounds that find applications as flavoring ingredients and the organisms are used ketogluconate by membrane-bound dehydrogenases in

as biological elements in sensor systems for the detection of alcohols and sugars [Svitel et al., 2006]. Many other useful organic compounds, such as pharmaceuticals and food additives, have asymmetric carbon atoms, and enatiomeric forms of these substances exist. In most cases, only one enantiomer is useful as a biologically active substance, the others not showing such activity and sometimes having a harmful effect. Therefore, the troublesome resolution of the racemic mixtures by means of organic synthetic processes for such substances is unavoidable. These facts indicate that new strategies for stereoselective biotransformations are needed. As mentioned above, G. oxydans $621 \mathrm{H}$ contains a great number of genes encoding oxidoreductases with unknown substrate spectra. Hence, it is tempting to speculate that the genome analysis together with the functional and structural analysis of novel dehydrogenases will result in new strategies for the synthesis of chiral alcohols, aldehydes, ketones and carboxylic acids. These techniques could then be used in industrial applications to produce enantiopure chemicals for drug synthesis or food industry.

\section{Acknowledgements}

We are indebted to our coworkers for their excellent work and we would like to thank Paul Schweiger and Shane Wesener for critical proofreading of the manuscript. We would also like to thank Prof. W. Liebl, Prof. G. Gottschalk and Prof. B. Bowien for their continued support. This work was supported by grants of the Competence Network Göttingen 'Genome Research on Bacteria' financed by the German Federal Ministry of Education and Research (BMBF).
References

\footnotetext{
Adachi O, Fujii Y, Ghaly MF, Toyama H, Shinagawa E, Matsushita K: Membrane-bound quinoprotein D-arabitol dehydrogenase of Gluconobacter suboxydans IFO 3257: a versatile enzyme for the oxidative fermentation of various ketoses. Biosci Biotechnol Biochem 2001a; 65:2755-2762.

-Adachi O, Fujii Y, Ano Y, Moonmangmee D, Toyama H, Shinagawa E, Theeragool G, Lotong N, Matsushita K: Membrane-bound sugar alcohol dehydrogenase in acetic acid bacteria catalyzes L-ribulose formation and NAD-dependent ribitol dehydrogenase is independent of the oxidative fermentation. Biosci Biotechnol Biochem 2001b;65:115125.

Adachi O, Moonmangmee D, Shinagawa E, Toyama H, Yamada M, Matsushita K: New quinoproteins in oxidative fermentation. Biochim Biopyhs Acta 2003;164:10-17.
} 
Asai T: Acetic Acid Bacteria: Classification and Biochemical Activities. Tokyo, University of Tokyo Press, 1968

- Bizouarn T, Althage M, Pedersen A, Tigerstrom A, Karlsson J, Johansson C, Rydstrom J: The organization of the membrane domain and its interaction with the $\mathrm{NADP}(\mathrm{H})$-binding site in proton-translocating transhydrogenase from E. coli. Biochim Biophys Acta 2002;1555:122-127.

-Bremus C, Herrmann U, Bringer-Meyer S, Sahm $\mathrm{H}$ : The use of microorganisms in L-ascorbic acid production. J Biotechnol 2006;124:196205.

- Buckley PA, Baz Jackson J, Schneider T, White SA, Rice DW, Baker PJ: Protein-protein recognition, hydride transfer and proton pumping in the transhydrogenase complex. Structure 2000;8:809-815.

-Chan HT, Anthony C: The $o$-type oxidase of the acidophilic methylotroph Acetobacter methanolicus. J Gen Microbiol 1991;137:693-704.

Chandra Raj K, Ingram LO, Maupin-Furlow JA: Pyruvate decarboxylase: a key enzyme for the oxidative metabolism of lactic acid by Acetobacter pasteurianus. Arch Microbiol 2001;176:443-451.

Chen C, Liu BY: Changes in major components of tea fungus metabolites during prolonged fermentation. J Appl Microbiol 2000;89: 834-839.

-Chinnawirotpisan P, Matsushita K, Toyama H, Adachi O, Limtong S, Theeragool G: Quinoprotein alcohol dehydrogenase is involved in catabolic acetate production, while NAD dependent alcohol dehydrogenase in ethanol assimilation in Acetobacter pasteurianus SKU1108. J Biosci Bioeng 2003;96:564-571.

Clarke DM, Loo TW, Gillam S, Bragg PD: Nucleotide sequence of the pntA and $p n t B$ genes encoding the pyridine nucleotide transhydrogenase of Escherichia coli. Eur J Biochem 1986; 158:647-653

- Cotton NPJ, White SA, Peake SJ, McSweeney S, Baz Jackson J: The crystal structure of an asymmetric complex of the two nucleotide binding components of proton-translocating transhydrogenase. Structure 2001;9 165-176.

-Czaja W, Krystynowicz A, Bielecki S, Brown RM Jr: Microbial cellulose - the natural power to heal wounds. Biomaterials 2006;27:145-151.

De Ley J: Comparative carbohydrate metabolism and a proposal for a phylogenetic relationship of the acetic acid bacteria. J Gen Microbiol 1963;24:31-50.

De Ley J, Swings J: Genus I. Acetobacter; in Krieg NR, Holt JG (eds): Bergey's Manual of Systematic Bacteriology. Baltimore, Williams \& Wilkins, 1984, vol 1, pp 268-274.

De Ley J, Swings J, Gossele F: The genus Gluconobacter; in Krieg NR, Holt JG (eds): Bergey's Manual of Systematic Bacteriology. Baltimore, Williams \& Wilkins, 1984, vol 1, pp 267-278.
Delmer DP, Amor Y: Cellulose biosynthesis. Plant Cell 1995;7:987-1000.

Deppenmeier U, Hoffmeister M, Prust C: Biochemistry and biotechnological applications of Gluconobacter strains. Appl Microbiol Biotechnol 2002;59:1513-1533.

-Drysdale GS, Fleet GH: Acetic acid bacteria in winemaking: a review. Am J Enol Vitic 1988 39:143-154.

-Dueweke TJ, Gennis RB: Proteolysis of the cytochrome d complex with trypsin and chymotrypsin localizes a quinol oxidase domain. Biochemistry 1991;30:3401-3406.

- Elfari M, Ha SW, Bremus C, Merfort M, Khodaverdi V, Herrmann U, Sahm H, Görisch H: A Gluconobacter oxydans mutant converting glucose almost quantitatively to 5-keto-Dgluconic acid. Appl Microbiol Biotechnol 2005;66:668-674.

Euzéby J: Validation of publication of new names and new combinations previously effectively published outside the IJSEM. Int J Syst Evol Microbiol 2005;55:983-985.

-Felder M, Gupta A, Verma V, Kumar A, Qazi GN, Cullum J: The pyrroloquinoline quinone synthesis genes of Gluconobacter oxydans. FEMS Microbiol Lett 2000;193:231-236.

Franke IH, Fegan M, Hayward C, Leonard G, Stackebrandt E, Sly LI: Description of Gluconacetobacter sacchari sp. nov., a new species of acetic acid bacterium isolated from the leaf sheath of sugar cane and from the pink sugar-cane mealy bug. Int J Syst Bacteriol 1999;49:1681-1693.

- Greenberg DE, Porcella SF, Stock F, Wong A, Conville PS, Murray PR, Holland SM, Zelazny AM: Granulibacter bethesdensis gen. nov., sp. nov., a distinctive pathogenic acetic acid bacterium in the family Acetobacteraceae. Int J Syst Evol Microbiol 2006;56: 2609-2616.

Greenfield S, Claus GW: Nonfunctional tricarboxylic acid cycle and the mechanism of glutamate biosynthesis in Acetobacter suboxydans. J Bacteriol 1972;112:1295-1301.

Gupta A, Singh VK, Qazi GN, Kumar A: Gluconobacter oxydans: its biotechnological applications. J Mol Microbiol Biotechnol 2001;3: 445-456.

Hauge JG, King TE, Cheldelin VH: Oxidation of dihydroxyacetone via the pentose cycle in Acetobacter suboxydans. J Biol Chem 1955; 214:11-26.

Hekmat D, Bauer R, Fricke J: Optimization of the microbial synthesis of dihydroxyacetone from glycerol with Gluconobacter oxydans. Bioprocess Biosyst Eng 2003;26:109-116.

Herrmann U, Merfort M, Jeude M, BringerMeyer S, Sahm H: Biotransformation of glucose to 5-keto-D-gluconic acid by recombinant Gluconobacter oxydans DSM 2343. Appl Microbiol Biotechnol 2004;64:86-90.

Hölscher T, Görisch H: Knockout and overexpression of pyrroloquinoline quinone biosynthetic genes in Gluconobacter oxydans 621 H. J Bact 2006;188:7668-7676.
Hoshino T, Sugisawa T, Shinjoh M, Tomiyama N, Miyazaki T: Membrane-bound D-sorbitol dehydrogenase of Gluconobacter suboxydans IFO 3255 - enzymatic and genetic characterization. Biochim Biophys Acta 2003; 1647: 278-288.

Jack R, De Zamaroczy M, Merrick M: The signal transduction protein $\mathrm{GlnK}$ is required for NifL-dependent nitrogen control of nif gene expression in Klebsiella pneumoniae. J Bacteriol 1999;181:1156-1162.

Jovanovic G, Weiner L, Model P: Identification, nucleotide sequence, and characterization of PspF, the transcriptional activator of the Escherichia coli stress-induced psp operon. J Bacteriol 1996;178:1936-1945.

Katsura K, Kawasaki H, Potacharoen W, Saono S, Seki T, Yamada Y, Uchimura T, Komagata K. Asaia siamensis sp. nov., an acetic acid bacterium in the $\alpha$-proteobacteria. Int J Syst Evol Microbiol 2001;51:559-563.

Kersters K, De Ley J: The occurrence of the Entner-Doudoroff pathway in bacteria. Antonie Van Leeuwenhoek 1968;34:393-408.

Klasen R, Bringer-Meyer S, Sahm H: Biochemical characterization and sequence analysis of the gluconate:NADP 5-oxidoreductase gene from Gluconobacter oxydans. J Bacteriol 1995; 177:2637-2643.

Kulhanek M: Microbial dehydrogenations of monosaccharides. Adv Appl Microbiol 1989; 34:141-181.

-Leisinger T: Untersuchungen zur Systematik und Stoffwechsel der Essigsäurebakterien. Zentbl Bakteriol Parasitenkd Infektionskrankh Hyg Abt II 1965;119:329-376.

Li Y, Chen J, Lun SY: Biotechnological production of pyruvic acid. Appl Microbiol Biotechnol 2001;57:451-459.

- Lisdiyanti P, Kawasaki H, Widyastuti Y, Saono S, Seki T, Yamada Y, Uchimura T, Komagata K: Kozakia baliensis gen. nov., sp. nov., a novel acetic acid bacterium in the $\alpha$-proteobacteria. Int J Syst Evol Microbiol 2002;52:813818

Macauley S, McNeil B, Harvey LM: The genus Gluconobacter and its applications in biotechnology. Crit Rev Biotechnol 2001;21:125.

Matsushita K, Shinagawa E, Adachi O, Ameyama M: Purification and characterization of cytochrome $o$-type oxidase from Gluconobacter suboxydans. Biochim Biophys Acta 1987;894:304-312.

Matsushita K, Nagatani Y, Shinagawa E, Adachi $\mathrm{O}$, Ameyama M: Effect of extracellular $\mathrm{pH}$ on the respiratory chain and energetics of Gluconobacter suboxydans. Agric Biol Chem 1989;53:2895-2902.

Matsushita K, Toyoma H, Adachi O: Respiratory chains and bioenergetics of acetic acid bacteria. Adv Microb Physiol 1994;36:247-301. 
Matsushita K, Fujii Y, Ano Y, Toyama H, Shinjoh M, Tomiyama N, Miyazaki T, Sugisawa T, Hoshino T, Adachi O: 5-Keto-D-gluconate production is catalyzed by a quinoprotein glycerol dehydrogenase, major polyol dehydrogenase, in Gluconobacter species. Appl Environ Microbiol 2003;69:1959-1966.

Matsushita K, Toyama H, Adachi O: Respiratory chains in acetic acid bacteria: membranebound periplasmic sugar and alcohol respirations; in Zannoni D (ed): Respiration in Archaea and Bacteria, vol 2: Diversity of Prokaryotic Respiratory Systems. Dordrecht, Springer, 2004, vol 2, pp 81-99.

Matsushita K, Inoue G, Theeragool J, Trcek H, Toyama H, Adachi O: Acetic acid production in acetic acid bacteria leading to their 'death' and survival; in Yamada M (ed): Survival and Death in Bacteria. Kerala/India, Research Signpost, 2005, pp 169-181.

Miller MJ, Gennis RB: The cytochrome d complex is a coupling site in the aerobic respiratory chain of Escherichia coli. J Biol Chem 1985;260:14003-14008.

-Moonmangmee D, Fujii Y, Toyama H, Theeragool G, Lotong N, Matsushita K, Adachi O: Purification and characterization of membrane-bound quinoprotein cyclic alcohol dehydrogenase from Gluconobacter frateurii CHM 9. Biosci Biotechnol Biochem 2001;65: 2763-2772.

Moonmangmee S, Kawabata K, Tanaka S, Toyama H, Adachi O, Matsushita K: A novel polysaccharide involved in the pellicle formation of Acetobacter aceti. J Biosci Bioeng 2002a; 93:192-200.

Moonmangmee D, Adachi O, Shinagawa E, Toyama H, Theeragool G, Lotong N, Matsushita K: L-Erythrulose production by oxidative fermentation is catalyzed by PQQ-containing membrane-bound dehydrogenase. Biosci Biotechnol Biochem 2002b;66:307318.

Olijve W: Glucose metabolism in Gluconobacter oxydans; PhD Thesis, University of Groningen, 1978

Olijve W, Kok JJ: Analysis of growth of Gluconobacter oxydans in glucose-containing media. Arch Microbiol 1979;121:283-290.

- Parmentier S, Beauprez J, Arnaut F, Soetaert W, Vandamme EJ: Gluconobacter oxydans NAD-dependent, D-fructose reducing, polyol dehydrogenases activity: screening, medium optimisation and application for enzymatic polyol production. Biotechnol Lett 2005;27:305-311.
Pronk JT, Levering PR, Olijve W, van Dijken JP: Role of NADP-dependent and quinoprotein glucose dehydrogenase in gluconic acid production by Gluconobacter oxydans. Enzyme Microb Technol 1989;11:160-164.

- Prust C, Hoffmeister M, Liesegang H, Wiezer A, Fricke WF, Ehrenreich A, Gottschalk G, Deppenmeier U: Complete genome sequence of the acetic acid bacterium Gluconobacter oxydans. Nat Biotechnol 2005;23: 195-200.

Ross P, Mayer R, Benziman M: Cellulose biosynthesis and function in bacteria. Microbiol Rev 1991;55:35-58.

- Sauer U, Canonaco F, Heri S, Perrenoud A, Fischer E: The soluble and membrane-bound transhydrogenases UdhA and PntAB have divergent functions in NADPH metabolism of Escherichia coli. J Biol Chem. 2004;279: 6613-6619.

-Schweiger P, Volland S, Deppenmeier U: Overproduction and characterization of two distinct aldehyde-oxidizing enzymes from Gluconobacter oxydans $621 \mathrm{H}$. J Mol Microbiol Biotechnol 2007;13:147-155.

- Shibata T, Ichikawa C, Matsuura M, Takata Y, Noguchi Y, Saito Y, Yamashita M: Cloning of a gene for D-sorbitol dehydrogenase from Gluconobacter oxydans G624 and expression of the gene in Pseudomonas putida IFO3738. J Biosci Bioeng 2000;89:463-468.

-Shinagawa E, Matsushita K, Adachi O, Ameyama M: Purification and characterization of 2-keto-D-gluconate dehydrogenase from Gluconobacter melanogenus. Agric Biol Chem 1981;45:1079-1085.

Shinagawa E, Matsushita K, Adachi O, Ameyama M: Purification and characterization of D-sorbitol dehydrogenase from membrane of Gluconobacter suboxydans var. $\alpha$. Agric Biol Chem 1982;46:135-141.

-Shinjoh M, Tazoe M, Hoshino T: NADPH-dependent L-sorbose reductase is responsible for L-sorbose assimilation in Gluconobacter suboxydans IFO 3291. J Bacteriol 2002;184: 861-863.

Sievers M, Swings J: Family II. Acetobacteraceae; in Garrity G, Brenner DJ, Krieg NR, Staley JT (eds): Bergey's Manual of Systematic Bacteriology. New York, Springer, 2005, vol 2c, pp 41-95.

- Sugiyama M, Suzuki S, Tonouchi N, Yokozeki K: Cloning of the xylitol dehydrogenase from Gluconobacter oxydans and improved production of xylitol from arabitol. Biosci Biotechnol Biochem 2003;67:584-591.
Svitel J, Tkac J, Vostiar I, Navratil M, Stefuca V, Bucko M, Gemeiner P: Gluconobacter in biosensors: applications of whole cells and enzymes isolated from Gluconobacter and Acetobacter to biosensor construction. Biotechnol Lett 2006;28:2003-2010.

Tong RC, Glavas NA, Bragg PD: Topological analysis of the pyridine nucleotide transhydrogenase of Escherichia coli using proteolytic enzymes. Biochim Biophys Acta 1991; 1080:19-28.

- Toyama H, Soemphol W, Moonmangmee D, Adachi O, Matsushita K: Molecular properties of membrane-bound FAD-containing D-sorbitol dehydrogenase from thermotolerant Gluconobacter frateurii isolated from Thailand. Biosci Biotechnol Biochem 2005; 69:1120-1129.

- Vangnai AS, Toyama H, De-Eknamkul W, Yoshihara N, Adachi O, Matsushita K: Quinate oxidation in Gluconobacter oxydans IFO3244: purification and characterization of quinoprotein quinate dehydrogenase. FEMS Microbiol Lett 2004;241:157-162.

-Van Heeswijk WC, Hoving S, Molenaar D, Stegeman B, Kahn D, Westerhoff HV: An alternative PII protein in the regulation of glutamine synthetase in Escherichia coli. Mol Microbiol 1996;21:133-146.

Weenk G, Olijve W, Harder W: Ketogluconate formation by Gluconobacter species. Appl Microbiol Biotechnol 1984;20:400-405.

Williams R, Cotton NP, Thomas CM, Jackson JB: Cloning and sequencing of the genes for the proton-translocating nicotinamide nucleotide transhydrogenase from Rhodospirillum rubrum and the implications for the domain structure of the enzyme. Microbiology 1994;140:1595-1604.

-Yamada Y, Hoshino K, Ishikawa T: The phylogeny of acetic acid bacteria based on the partial sequences of $16 \mathrm{~S}$ ribosomal RNA: the elevation of the subgenus Gluconacetobacter to the generic level. Biosci Biotechnol Biochem 1997;61:1244-1251.

- Yamada Y, Hosono R, Lisdyanti P, Widyastuti Y, Saono S, Uchimura T, Komagata K: Identification of acetic acid bacteria isolated from Indonesian sources, especially of isolates classified in the genus Gluconobacter. J Gen Appl Microbiol 1999;45:23-28.

Yamada Y, Katsura K, Kawasaki H, Widyastuti Y, Saono S, Seki T, Uchimura T, Komagata K: Asaia bogorensis gen. nov., sp. nov., an unusual acetic acid bacterium in the $\alpha$-Proteobacteria. Int J Syst Evol Microbiol 2000;50: 823-829. 